\title{
Koreksi Keratokonus dengan Lensa Kontak Rigid Gas Permeable (RGP)
}

\author{
Rozy Oneta, Rinda Wati
}

\begin{abstract}
Abstrak
Keratokonus adalah suatu kelainan non inflamasi kornea yang ditandai oleh penipisan kornea yang progresif yang mengakibatkan steepening dan penonjolan kornea. Perubahan pada kornea ini mengakibatkan timbulnya astigmat ireguler dan sikatriks kornea, yang akan mengurangi the best-corrected visual acuity (BCVA) dari pasien. Penyakit ini dapat menyerang berbagai ras dan tidak terdapat perbedaan yang signifikan antara insiden keratokonus antara pria dan wanita. Penyakit ini bersifat bilateral (96\%) tapi asimetris antara kedua mata. Onset dari keratokonus biasanya terjadi pada usia pubertas hingga usia awal 20 tahun dan cenderung progresif hingga dekade ketiga atau keempat kehidupan. Pasien dengan keratokonus mengeluhkan penurunan tajam penglihatan dan riwayat koreksi kacamata yang berulang-ulang. Lensa Kontak Rigid (RGP) merupakan modalitas terapi keratokonus yang paling optimal, karena memberikan visus yang baik dengan membentuk permukaan optik baru yang reguler.
\end{abstract}

Kata kunci: keratokonus, astigmat ireguler, lensa kontak rigid

\section{Abstract}

Keratoconus is a non-inflammatory disorder of the cornea characterized by progressive thinning of the cornea that caused steepening and bulging of the cornea. This change in the cornea causes an irregular astigmatism and corneal scarring, which will reduce the best corrected visual acuity (BCVA) of the patient. This disease can attack various races and does not show a significant difference between men and women. This disease is bilateral (96\%) but asymmetrical between the two eyes. The onset of keratoconus usually occurs at the age of puberty into early-20s and tends to be progressive until third to fourth decade of life when it becomes relatively stable. Patients with keratoconus complain of a decline in visual acuity and repeated correction of glasses. Rigid Contact Lens (RGP) is the most optimal modality of keratoconus management, because it provides good vision by making regular new optical surfaces.

Keywords: keratokonus, irregular astigmatism, rigid contact lenses

Affiliasi penulis: Dinas Kesehatan Kota Jambi

Korespondensi : rozyoneta@gmail.com, rindawatispm@yahoo.com Telp: 081374004004

\section{PENDAHULUAN}

Keratokonus adalah suatu kelainan non inflamasi kornea yang ditandai oleh penipisan kornea yang progresif yang mengakibatkan steepening dan penonjolan kornea. ${ }^{1}$ Perubahan pada kornea ini mengakibatkan timbulnya astigmat ireguler dan sikatriks kornea, yang akan mengurangi the bestcorrected visual acuity (BCVA) dari pasien. ${ }^{2}$
Pasien dengan keratokonus mengeluhkan penurunan tajam penglihatan dan riwayat koreksi kacamata yang berulang. Pada pemeriksaan dengan slit-lamp dapat ditemukan tanda penipisan kornea dan peningkatan kurvatura kornea. Pada beberapa kasus, bentuk konus dari kornea sangat jelas sehingga dapat terlihat dengan mata telanjang. Hasil keratometri ( $K$ readings) menjadi makin steep hingga tidak lagi berada dalam range instrumen dan mires mengalami distorsi. $^{3}$

Analisis pola topografi kornea dan pachymetry adalah pemeriksaan yang penting untuk memastikan 
diagnosis keratokonus. Gambaran khas dari peta topografi keratokonus adalah adanya focal steepening pada zona penonjolan kornea yang dikelilingi oleh zona penurunan power yang konsentris. Perbedaan yang signifikan pada ketebalan kornea sentral dan minimum berguna dalam menentukan severity keratokonus. $^{4}$

Lensa Kontak Rigid (RGP) merupakan modalitas terapi keratokonus yang paling optimal, karena memberikan visus yang baik dengan membentuk permukaan optik baru yang reguler. Apabila lensa kontak tidak dapat mengatasi kelainan ini, maka perlu dipertimbangkan tindakan bedah. ${ }^{5}$

\section{KASUS}

Seorang pasien perempuan usia 21 tahun datang ke poliklinik mata RSUP Dr.M.Djamil Padang dengan keluhan penglihatan Kedua mata kabur sejak 4 tahun yang lalu, yang semakin lama semakin kabur. Penglihatan kabur dirasakan saat melihat jauh maupun dekat. Riwayat memakai kacamata awalnya 4 tahun yang lalu, pasien sudah $3 x$ berganti kacamata dalam rentang waktu 1,5 tahun karena kacamata dengan cepat dirasa tidak cocok lagi. Sejak 1,5 tahun yang lalu pasien tidak lagi memakai kacamatanya. Untuk dapat membaca dengan jelas pasien harus mendekatkan objek yang dilihat ke mata. Pasien mengatakan tidak ada riwayat alergi atau alergi pada mata, dan tidak ada keluarga yang menderita penyakit yang sama. Pasien baru saja lulus dari perguruan tinggi dan berencana untuk bekerja sebagai pengajar pada salah satu pusat bimbingan belajar di kota asalnya.

Pada pemeriksaan mata didapatkan tajam penglihatan pada mata kanan dan mata kiri adalah 2/60 (hitung jari pada jarak 2 meter). Koreksi refraksi hanya dapat dilakukan secara subyektif, dengan hasil koreksi kacamata untuk mata kanan S-3,50C2,50(100) dan mata kiri S-3,50C-1,25(90). Koreksi tersebut menyebabkan tajam penglihatan hanya maju menjadi 20/80F. Pada pemeriksaan slitlamp tampak kornea berbentuk konus dengan penipisan dan sikatrik di bagian sentral. Pemeriksaan status oftalmologis lain dalam batas normal. Pemeriksaan keratometri harus dilakukan dengan penambahan lensa $+2,50 \mathrm{D}$ pada mata kanan dan $+1,25$ D pada mata kiri. Hasil keratometri mata kanan: $\mathrm{KH}=51,375 \mathrm{D}, \mathrm{KV}: 56,00 \mathrm{D}$, tampak bentuk mires mengalami distorsi. Hasil keratometri mata kiri: $\mathrm{KH}=55,20 \mathrm{D}, \mathrm{KV}: 58,50 \mathrm{D}$, tampak bentuk mires mengalami distorsi.
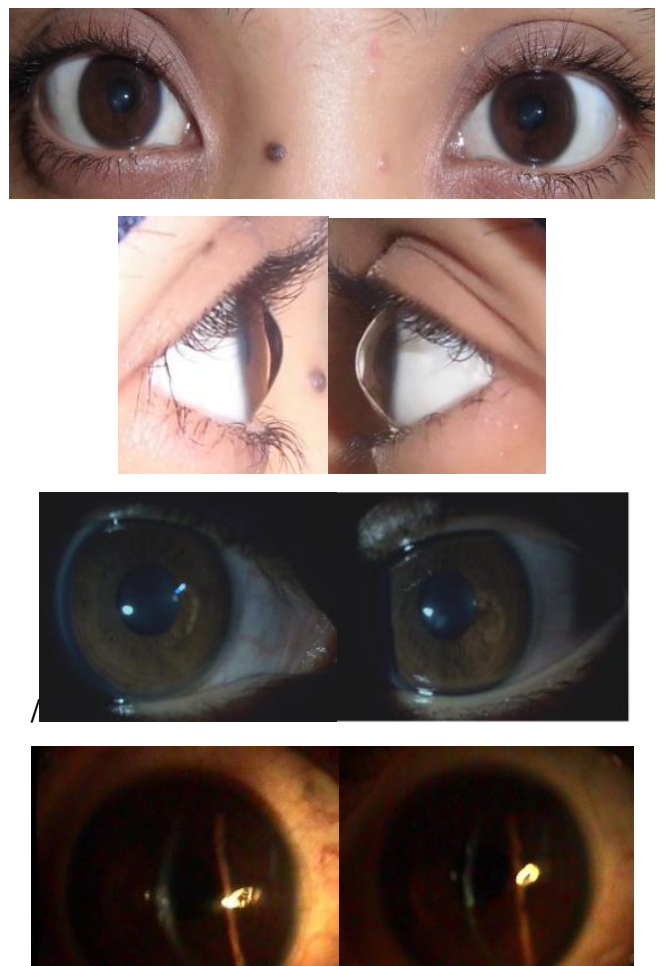

Gambar 1. Hasil pemeriksaan slitlamp

Pasien didiagnosis dengan keratokonus pada kedua mata. Pasien dijelaskan mengenai penyakitnya, kemudian dianjurkan memakai RGP agar penglihatannya dapat lebih optimal pasien. Setelah berembuk dengan keluarga, pasien bersedia untuk memakai RGP. Karena saat itu kami belum memiliki trial RGP untuk keratokonus, pasien dirujuk untuk fitting RGP ke RS di Jakarta.

Pasien kontrol lagi setelah \pm 5 bulan kemudian dengan membawa hasil pemeriksaan dan fitting RGP yang akhirnya dilakukan di RS swasta di Jakarta. Resep RGP yang didapatkan untuk mata kanan adalah 5.90/-14.50/8.6, dan untuk mata kiri 6.00/13.00/8.8. Tajam penglihatan dengan RGP lebih baik daripada dengan kacamata yaitu 20/40. 

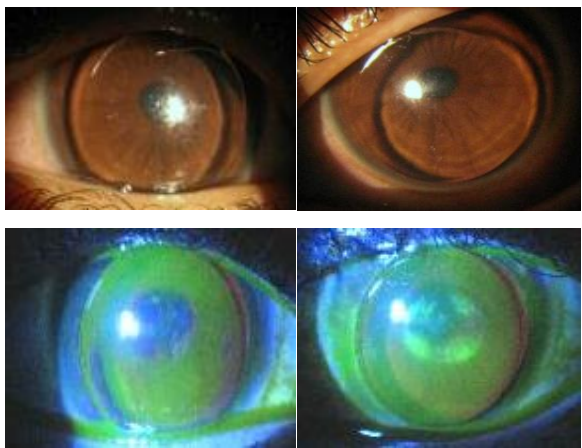

Gambar 2. Gambaran kornea pasien

Pasien diajarkan cara memasang dan melepaskan RGP, membersihkan RGP, cara adaptasi pemakaian RGP dan dijadwalkan untuk kontrol 1-2 minggu kemudian. Pasien kontrol 2 minggu kemudian dan telah berhasil dalam adaptasi pemakaian RGP. Selanjutnya pasien dijadwalkan kontrol tiap 6 bulan. Tajam penglihatan dan kualitas penglihatan dengan RGP tetap stabil selama kontrol, dan tidak ditemukan efek samping penggunaan RGP pada mata.

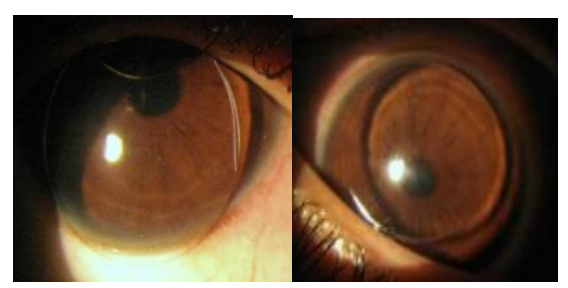

Gambar 3. Pemasangan RGP

\section{PEMBAHASAN}

Dilaporkan kasus keratokonus kedua mata pada seorang perempuan umur 21 tahun. Keratokonus adalah suatu kelainan non inflamasi kornea yang ditandai oleh penipisan kornea yang progresif, steepening, dan penonjolan kornea. Keratokonus biasanya bermanifestasi pada awal masa pubertas sampai awal usia 20-an. ${ }^{1}$ Keratokonus merupakan kelainan bilateral pada 96\% kasus, tidak terdapat perbedaan yang signifikan insiden keratokonus antara mata kanan dengan mata kiri, atau antara jenis kelamin laki-laki dengan perempuan. ${ }^{2}$

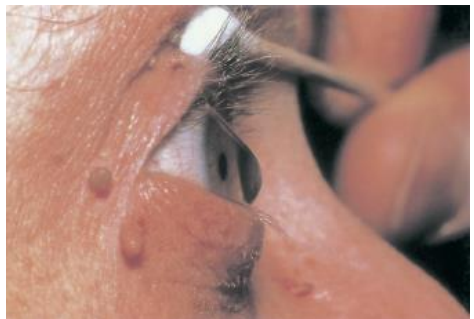

Gambar 4. Gambaran kornea dengan Keratokonus

Anamnesis didapatkan bahwa penglihatan kedua mata kabur sejak 4 tahun yang lalu, yang semakin lama semakin kabur. Kabur dirasakan saat melihat jauh maupun dekat, pasien harus mendekatkan objek yang akan dilihat ke mata agar bisa membaca dengan jelas. Didapatkan pula riwayat berganti-ganti kacamata, karena kacamata dengan cepat dirasakan tidak cocok lagi. Berdasarkan kepustakaan, penurunan visus yang bertahap sering menjadi gejala klinis awal dari keratokonus. Pandangan kabur terjadi baik untuk jarak dekat maupun jauh. Pasien dapat melihat lebih jelas dengan memegang bahan bacaan sangat dekat ke mata. Pandangan mungkin tidak sepenuhnya kabur, tetapi mengalami distorsi; huruf-huruf tampak meragukan, dan bagian-bagian dari huruf dapat hilang atau berubah. Sebagai tambahan, apabila kondisi ini sebelumnya belum terdiagnosa, pasien dapat memiliki beberapa pasang kacamata, yang tidak satupun memuaskan. $^{3}$

Etiologi keratokonus pada pasien ini diduga adalah genetik, walau dari anamnesa tidak ada keluarga yang menderita penyakit yang sama. Dalam kepustakaan disebutkan bahwa etiologi keratokonus masih belum diketahui, akan tetapi penyakit ini diduga merupakan suatu kelainan genetik. ${ }^{6}$ Antara $6 \%$ dan $16 \%$ pasien keratokonus memiliki riwayat penyakit keluarga, akan tetapi, prevalensi, insiden, dan hubungan familial sulit untuk dibuktikan karena kondisi penyakit ini yang bervariasi, mulai dari kondisi yang asimptomatis hingga sikatrik kornea yang membutuhkan transplantasi kornea. Keratokonus juga sering ditemukan pada sindroma genetik seperti 
Sindroma Down, sehingga makin menyokong hipotesa genetik. $^{3}$

Pada status oftalmologis ditemukan penurunan visus yang disertai penurunan Best-Corrected Visual Acuity (BCVA) dengan koreksi kacamata. Kepustakaan menyebutkan bahwa penurunan visus yang progresif pada keratokonus disebabkan oleh miopia progresif dan astigmat ireguler. ${ }^{2}$ Seiring dengan progresifitas keratokonus, perubahan bentuk kornea akan semakin memperberat astigmat ireguler, yang tidak dapat dikoreksi dengan maksimal menggunakan kacamata. ${ }^{7}$

Pada pemeriksaan slit-lamp tampak kornea yang berbentuk konus, dengan penipisan dan sikatrik dibagian sentral. Sedangkan tanda klasik lainnya, yaitu Vogt's striae dan Fleischer's line, tidak ditemukan pada pasien ini. Dalam kepustakaan dikatakan, diagnosa keratokonus ditegakkan apabila ditemukan penipisan dan penonjolan kornea yang terlokalisir pada pemeriksaan slit-lamp. Tanda awal ini dapat sangat ringan dan mudah terlewatkan. Pada beberapa kasus, bentuk konus dari kornea sangat jelas sehingga dapat terlihat dengan mata telanjang. Dalam kepustakaan juga disebutkan bahwa Vogt's striae dan Fleischer's line ditemukan pada pemeriksaan slit-lamp pada keratokonus ringan sampai moderat. Vogt's striae relatif lebih sering ditemukan, merupakan garisgaris vertikal atau oblik bewarna putih yang berada pada stroma posterior atau membran descemet pada apeks konus akibat peregangan lamellae kornea. Garis-garis ini menghilang dengan melakukan penekanan pada limbus. Fleischer's line adalah garis bewarna kuning-coklat hingga kehijauan disekeliling dasar konus, merupakan deposit hemosiderin pada epitel basal, paling baik dilihat dengan cahaya biru kobalt. Sedangkan pada keratokonus yang lanjut, terbentuk sikatrik superfisial pada apeks konus. ${ }^{4}$

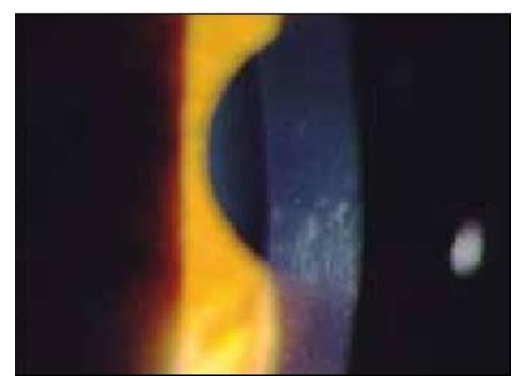

Gambar 5. Vogt's striae ${ }^{2}$

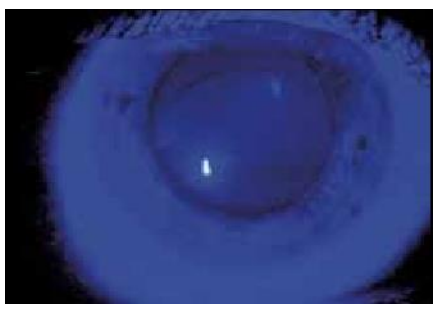

Gambar 6. Fleicher's ring ${ }^{2}$

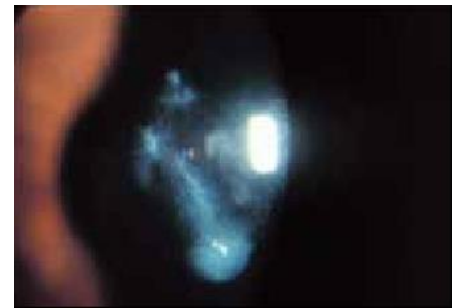

Gambar 7. Sikatrik kornea ${ }^{2}$

Konfirmasi diagnosis klinis mendapatkan data kuantitatif nilai akurat dari kurvatura kornea dan ketebalan kornea. Nilai kurvatura kornea dapat dihitung menggunakan keratometri. Pada pemeriksaan keratometri pasien, tampak keratometric mires mengalami distorsi, dan tidak dapat disatukan. Nilai kurvatura kornea pasien juga jauh melebihi nilai kurvatura keratometer, sehingga pembacaan keratometri dilakukan dengan menambahkan lensa $+1,25$ dan $+2,50$ di depan lensa obyektif pada keratometer. Hasil keratometri (K-readings) mata kanan pasien adalah : $\mathrm{KH}=51,375 \mathrm{D} \sim 6,63 \mathrm{~mm} ; \mathrm{KV}$ $=56,00 \mathrm{D} \sim 6,00 \mathrm{~mm}(+2,50 \mathrm{D})$. Dan hasil keratometri mata kiri pasien adalah : $\mathrm{KH}=55,20 \mathrm{D} \sim 6,175 \mathrm{~mm}$; $\mathrm{KV}=58,50 \mathrm{D} \sim 5,83 \mathrm{~mm}$. Dalam kepustakaan dikatakan tanda awal dari keratokonus adalah adanya distorsi dari mires pada pemeriksaan keratometri. Hasil keratometri pada keratokonus juga akan didapatkan steepening kurvatura kornea melebihi nilai normal. Hasil keratometri mata normal berkisar antara $43 \mathrm{D}$ sampai $48 \mathrm{D}$, sedangkan pada keratokonus hasil keratometri akan lebih dari $48 \mathrm{D}$. Apabila keratokonus berlanjut melebihi nilai kurvatura keratometer, lensa $+1,25 \mathrm{D}$ dan $+2,50$ dapat diletakkan di depan lensa objektif untuk menambahkan $8 \mathrm{D}$ dan $16 \mathrm{D}$ pada pembacaan keratometri. $^{3}$

Pemeriksaan topografi kornea (video keratografi) sangat berguna dalam mengkonfirmasi diagnosis dan monitoring keratokonus. Lokasi apeks 
dan progresifitas penyakit dapat dengan mudah diamati dengan mengevaluasi warna pada peta topografi kornea. ${ }^{3}$ Karakteristik keratokonus pada peta topografi kornea adalah terdapatnya zona peningkatan kekuatan kornea yang dikelilingi oleh zona penurunan kekuatan kornea, asimetri kekuatan kornea superior dan inferior, dan perubahan arah aksis yang paling steep pada bagian atas dan bawah dari meridian horizontal. ${ }^{8}$ Tiga gambaran cone atau konus pada keratokonus yaitu nipple, oval atau globus. Nipple cone ukurannya paling kecil dan letaknya lebih di sentral daripada dua bentuk lain. Oval cone letaknya inferior dari aksis visual, sedangkan globus cone menggambarkan area steepening kornea yang luas. ${ }^{9}$

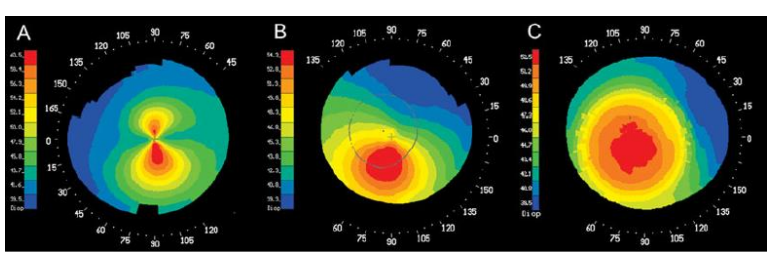

Gambar 8. Peta topografi kekuatan kornea disertai skala (dalam dioptri) menunjukkan tiga morfologi konus pada keratokonus. A: Nipple cone. B: Oval cone. C: Globus cone. ${ }^{9}$

Peta kornea yang digunakan untuk fitting lensa kontak adalah aksial (sagital), tangensial (lokal) dan elevation maps, yang masing-masing memiliki kelebihan dan aplikasi spesifik untuk fitting lensa kontak. Peta aksial menyediakan informasi mengenai perkiraan bentuk kornea, dapat sangat berguna untuk menentukan parameter lensa kontak, khususnya kurvatura posterior. Peta tangensial sangat membantu untuk menentukan posisi, ukuran dan bentuk dari suatu gambaran spesifik pada permukaan kornea yang memerlukan perhatian khusus, seperti: pterigium, keratokonus atau sikatrik kornea. Sedangkan elevation maps menyediakan informasi mengenai alignment lensa kontak terhadap permukaan kornea. $^{10}$

Ketebalan kornea pada bagian sentral mata kanan adalah $343 \mu \mathrm{m}$, dan mata kiri adalah $382 \mu \mathrm{m}$. Dari kepustakaan diketahui ketebalan kornea bagian sentral adalah $540 \pm 30 \mu \mathrm{m}$, sedangkan pada keratokonus akan terjadi penipisan ketebalan kornea bagian sentral $(443 \pm 64 \mu \mathrm{m}){ }^{2}$
Pada pasien ini didapatkan BCVA dengan RGP lebih baik daripada BCVA dengan koreksi kacamata. Kepustakaan menyebutkan pada derajat awal dari penyakit, kacamata dapat memperbaiki visus ke level yang masih dapat diterima (20/40 atau lebih baik). Seiring dengan progresifitas penyakit, miopia dan astigmat iregular akan semakin berat sehingga koreksi visus dengan kacamata tidak dapat lagi diterima pasien. ${ }^{6}$

Keratokonus paling baik dikoreksi dengan RGP), bahkan pada derajat awal penyakit dimana koreksi dengan kacamata masih merupakan pilihan. Hal ini karena lensa kontak rigid paling baik dalam mengkoreksi astigmat ireguler dan aberasi sekunder yang timbul akibat iregularitas kornea dengan membentuk permukaan optik baru yang reguler. Lensa kontak rigid akan menetralisir sebagian besar distorsi/aberasi optik dari permukaan anterior kornea dan visus akhir akan meningkat beberapa baris pada acuity chart. ${ }^{5}$

\section{SIMPULAN}

Keratokonus adalah suatu kelainan noninflamasi bilateral, biasanya asimetris, pada kornea. Keratokonus ditandai oleh penipisan kornea yang progresif, steepening, anterior protusion dan coneal ectasia. Keratokonus biasanya bermanifestasi pada awal masa pubertas sampai awal usia 20-an. Perubahan kornea pada keratokonus menyebabkan astigmat ireguler dan sikatrik kornea, yang akan penurunkan BCVA pada pasien. Pemeriksaan topografi kornea sangat berguna dalam mengkonfirmasi diagnosa, dan manajemen dari keratokonus (fitting lensa kontak). Lensa kontak rigid adalah terapi terbaik untuk keratokonus karena dapat memberikan visus yang baik dengan membentuk permukaan optik baru yang reguler.

\section{UCAPAN TERIMA KASIH}

Terima kasih saya ucapkan kepada Ketua Program studi IImu Kesehatan Mata Program Pendidikan Dokter Spesialis Fakultas Kedokteran Universitas Andalas dan Ketua Bagian IImu Kesehatan Mata RS Dr.M.Djamil Padang yang telah membantu dalam penulisan laporan kasus ini. 


\section{DAFTAR PUSTAKA}

1. Cantor LB, Rapuano CJ, Cioffi GA. External diseases and cornea. San Fransisco: American Academy of Ophthalmology; 2016.hlm.228-33.

2. Sorbara L. Correction of keratoconus with GP lenses. Canada: Centre for Contact Lens Research. 2014 (diakses 5 Januari 2019). Tersedia dari: https://www.artoptical.com/storage/ docs/Correction of Keratoconus with GP.pdf

3. Bennet ES, Henry VA. Clinical manual of contact lenses. Edisi ke-4. Philadelphia: Lippincott Williams \& Wilkins; 2014.hlm. 518-77.

4. Del-Viejo LR, Garcia-Montero M, HernandezVerdejo JL, Garcia-Lazaro S, Gomez-Sanz FJ, Lorente-Velasquez A. Nonsurgical procedures for keratoconus management. Journal of Ophthalmology. 2017;1:1-17.

5. Mohammadpour M, Heidari Z, Hashemi $H$. Updates on management for keratoconus. Journal of Current Ophthalmology. 2017;30(2018):110-24.

6. Moschos MM, Nitoda E, Georgoudis P, Balidis M, Karageorgiadis E, Kozeis N. Contact lenses for keratoconus - current practise. The Open Ophthalmology Journal. 2017;11:241-51.

7. Vazirani J, Basu S. Keratoconus: current perspectives. Clinical Ophthalmology. 2013;7:2019-30.

8. Downie LE, Lindsay RG. Contact lens management of keratoconus. Clinical and Experimental Optometry. 2015;98:299-311.

9. Nejabat M, Khalili MR, Dehghani C. Cone location and correction of keratoconus with rigid gas permeable contact lenses. Contact Lens \& Anterior Eye. 2012;35:17-21.

10. Shetty R, Kaweri L, Pahuja N, Nagaraja H, Wadia $\mathrm{K}$, Jayadev $\mathrm{C}$, et al. Current review and simplified "five-point management algorithm" for keratoconus. Indian Journal Ophthalmology 2015;63(1):46-53. 